REPORTS

\title{
Emergency Medical Conference South Africa, October 1998 - A report on proceedings and clinical visits
}

\author{
Lt Col TJ Hodgetts
}

MB BS(Hons), FRCP, FFAEM, DipIMC RCSEd, DipMedEd, RAMC

Consultant and Speciality Adviser in Accident and Emergency Medicine

MDHU Frimley Park Hospital, Portsmouth Road, Frimley, Surrey GU16 5UJ

\author{
Professor of Emergency Medicine and Trauma, \\ University of Surrey
}

e-mail: tim.hodgetts@virgin.net

\section{Introduction}

The effective management of serious injury is central to the operational philosophy of the Defence Medical Services. South Africa, and Johannesburg in particular, has the reputation of being the 'trauma capital of the World'. An advanced system of trauma management has been developed through necessity, yet there is no recognised specialty of emergency medicine or any formal training in this discipline.

In October 1998 the Speciality Adviser in Accident and Emergency Medicine visited South Africa with the following objectives:

- To attend and present at a landmark conference to launch emergency medicine as a specialty in South Africa;

- To observe the pre-hospital and hospital trauma services in Johannesburg;

- To establish personal links with the South African Military Health Service (SAMHS) and civilian consultants in trauma surgery that may facilitate training attachments for other service personnel.

\section{Conference}

This inaugural 3-day conference, entitled Pre-hospital and Emergency Medicine, was a collaboration between the South African College of Medicine, the Australasian College of Emergency Medicine, and the Faculty of Pre-hospital Care of the Royal College of Surgeons of Edinburgh. There were further speakers from the United States, Canada and Europe. It was the objective of the conference organisers to provide a forum to learn from best practice in emergency medicine, and specifically from existing training packages in the specialty.

Lt Col Hodgetts spoke in the plenary session on day 1 on $A$ systematic international approach to major incident training, with reference to the Major Incident Medical Management and Support (MIMMS) course. This course was established in 1994 in Manchester, and has subsequently spread across the United Kingdom, and to Australia and Japan. The first course in the Netherlands will be held in 1999. A simple, stepwise approach is taught to the management of any incident involving multiple casualties. The principles are equally applicable to a civilian and military audience - and three courses have been run in the UK for military personnel, with plans for it to be incorporated regularly into the calendar of activities at the Royal Defence Medical College. Evidence was presented to support the effectiveness of the MIMMS teaching programme, and its adaptability to meet the training requirements in South Africa was discussed.

Approaches have subsequently been made to Lt Col Hodgetts for this course to be established in South Africa.

\section{Military visits}

At the invitation of the Surgeon General SAMHS, Lt Col Hodgetts and Lt Col Kremer OAM RAAMC(V) visited three military institutions.

1.The SAMHS Academy. This has similar functions to the Defence Medical Services Training Centre, but additionally provides undergraduate and postgraduate training for nurses, a one year military training programme for medical cadets prior to starting pre-clinical studies, and has a medical Staff College. Presentations were given by the Commandant and the Chief Instructor.

2.The Institute for Aviation Medicine to view research facilities and the hyperbaric unit.

3.1 Military Hospital, Pretoria. A presentation was given by the Commanding Officer, Brigadier General A Lotter SM MMM OStJ of the 'peace' and operational functions of a military hospital with Level 1 trauma facilities. A tour of the hospital concentrated on the emergency and intensive care departments.

\section{Clinical attachments and visits}

Johannesburg General Hospital Trauma Unit. This was organised by the Director and Principal Trauma Surgeon in the unit, Dr Ken Boffard. There are $\sim 40$ trauma resuscitations per week, with $\sim 70 \%$ of these being penetrating trauma. In comparison, MDHU Frimley Park averages 17 patients per month who fulfill the criteria to activate a trauma team (1) and 82 'major trauma' patients per year characterised by a New Injury Severity Score of $\geq 16$ (a more reliable indicator of major trauma than the traditional Injury Severity Score) (2). Activities included:

- Attendance at the trauma clinical case meeting;

- Attendance on the Trauma ICU and Trauma Ward clinical round;

- Observation of trauma resuscitation in the trauma receiving room, over a 12 hour period.

Resuscitation followed standard ATLS guidelines and was led by the general surgeons, who also provided the advanced airway skills. The trauma team was smaller than all that have been observed in the UK, but it was well practised and roles were clearly identified.

'Flight for Life' helicopter. This is the busiest helicopter emergency medical service in the World, with around 1800 primary retrieval flights per year. The flights are principally to attend seriously injured patients at the scene of the incident. A doctor (SHO general surgeon equivalent), nurse, and a paramedic provide the tretment. On this occasion the Specialty Adviser A\&E took the place of the paramedic for a 12-hour shift. Cases attended included: 
1. Adult male, multiple gunshot wounds to the abdomen.

2.4-year-old male, deaf and dumb, airway obstruction following severe dog bites to the face and throat.

This was a highly professional service. Cases were observed to be taken to either township hospitals (where there were minimal resuscitation facilities-in case 1 above, a porter and a disinterested nurse), Johannesburg General Hospital, or Milpark Private Hospital. The latter hospital was adjacent to Johannesburg General Hospital and was staffed by a resident consultant trauma surgeon on weekly rotation with the general hospital. There was a stark contrast with facilities available in the public sector, including a fully staffed and equipped 30 -bed trauma intensive care unit.

South African Police Flying Squad, Medical Support Unit. Dr Frank Plani, Deputy Director of the Trauma Unit at Johannesburg General Hospital, has identified the need to provide front-line support to the police. In his conference address he stated that over 1000 police officers are killed on duty each year. He has developed a training program for police medics, and is one of a growing number of doctors in the reserve police force who are on duty to provide medical support in operations. The objective of an 8-hour Friday night shift with the flying squad was to observe the role of the police medic. This was a breathtaking experience. They are police officers first, and medics second.

Baragwaneth Hospital. Two visits were made to the 'emergency department' of this hospital, with an escort provided by Dr Carol Benn, Principal Trauma Surgeon. This unit is recognised as the busiest trauma unit in the World (outside a war zone) and serves the 3 million population of Soweto (South Western Township). Up to 30-40 seriously injured may be awaiting treatment at any time in the "surgical pit". There is a very high proportion of penetrating trauma (personal assualt with firearm, knife and axe). Resuscitation is performed by disturbingly junior staff (often medical students), ס the more senior staff being entrenched in the operating theatre.

Discussions with Dr Benn identified an overwhelming desire to accommodate military medical trainees on clinical attachment. A personal observation was the lack of audit or research as a result of the clinical workload. Any such clinical attachment must take the opportunity to learn from audit or research of this unique cohort of seriously injured patients.

\section{Summary}

The South Africans are keen to adopt the Major Incident Medical Management and Support course, developed in the UK.

South Africa can provide an excellent training ground for $\vec{\circ}$ military personnel in the triage, resuscitation and surgical management of the patient with penetrating trauma. Johannesburg General Hospital has a high quality training system under the direction of Dr Ken Boffard. The nearby Baragwaneth Hospital is the closest to military surgical practice one can probably get in a civilian setting. There is an unprecedented opportunity for clinical skills training, and a wealth of research opportunites.

\section{REFERENCES}

1. Hodgetts $\mathrm{T}$, Parkhouse $\mathrm{H}$, CobB B. Major Trauma Clinical Effectiveness Project, Annual Report 1997-8. Camberley, December 1998.

2. OSLER T, BAKER S, LONG W. A modification of the Injury Severity Score that both improves accuracy and simplifies scoring. J Trauma 1997; 43: 922-926. 